\title{
Deformação rúptil em rochas do magmatismo Penatecaua no domo de Monte Alegre (PA)
}

\author{
Isabella Françoso Rebutini Figueira ${ }^{1 *}$, Eduardo Salamuni', Fernando Mancini ${ }^{2}$
}

\begin{abstract}
Resumo O domo de Monte Alegre se destaca em meio à planície do rio Amazonas, em sua margem esquerda, como uma notável elevação topográfica situada aproximadamente a $10 \mathrm{~km}$ a noroeste da cidade homônima, no estado do Pará. A partir de sua descoberta, muitas têm sido as hipóteses para a gênese do domo, entretanto, somente em 1975, Montalvão e Oliveira associaram a geometria dômica às intrusões toleíticas básicas, que moldaram a estrutura braquianticlinal em forma de elipsoide, com $30 \mathrm{~km}$ de comprimento e $20 \mathrm{~km}$ de largura. Por meio de pesquisas da morfoestrutura do domo, das camadas sedimentares basculadas e, em particular, dos sistemas de fraturas em rochas intrusivas geradas pelo magmatismo Penatecaua, foi possível verificar que a atual estrutura braquianticlinal do domo tem origem deformacional devido a pelo menos duas fases de deformação (F1 e F2) Jurocretácea, que geraram, consequentemente, dois sistemas de cisalhamento rúptil, podendo ser localmente dúctil quando a reologia é propícia. Tais fases de deformação foram correlacionadas, por meio da análise da paleotensão, com regimes tectônicos regionais, como o Diastrofismo Juruá, confirmando-se que tiveram influência decisiva na deformação finita do domo.
\end{abstract}

Palavras-chave: Domo de Monte Alegre; análise estrutural; magmatismo Penatecaua.

\begin{abstract}
Ruptile deformation in Penatecaua magmatic rocks at the dome of Monte Alegre (PA). Monte Alegre dome, which stands out amid the plains of the Amazon River, is a topographic high on the left bank of the river, about $10 \mathrm{~km}$ northwest of the city of the same name, in Pará. From its discovery, many hypotheses have been for the genesis of the dome, however only in 1975 Montalvão and Oliveira associated geometry with tholeitic intrusion that have shaped as braquianticlinal structure, with ellipsoid-shaped $30 \mathrm{~km}$ long and $20 \mathrm{~km}$ wide. Through morphostructural researchers of the dome, of the rock layers tilted and, in particular, systems of fractures in intrusive rocks generated by magmatism Penatecaua was possible to verify that the current braquianticlinal structure of the dome, originated as a result of deformation at least two phases of deformation (F1 and F2) Juro-Cretaceous, which generated at least two systems of locally ductile and brittle shearing, when the rheology is ripe. Correlated these stages of deformation, by analyzing the paleostress with regional tectonic regimes, such as diastrophic Juruá, confirming that it had a decisive influence on the finite deformation of the dome.
\end{abstract}

Keywords: Monte Alegre dome; structural analisys; Penatecaua Magmatism.

INTRODUÇÃO O domo de Monte Alegre, morfoestrutura eojurássica que se destaca em meio à planície do rio Amazonas, é uma elevação topográfica localizada na margem esquerda, situada a aproximadamente $10 \mathrm{~km}$ a sudoeste da cidade homônima, no estado do Pará(Fig. 1). Esta região montanhosa há muito tem atraído a atenção de pesquisadores de todo o mundo, seja por suas características geomorfológicas, seja pelo seu vasto e rico sítio arqueológico. Os primeiros estudos registrados sobre o domo são do final do século XIX, entre os anos de 1870 e 1874, quando Fred Hartt, que participava de expedição científica, relatou a ocorrência de "região montanhosa, tabular, levemente arredondada, com caimentos tanto para leste quanto para oeste, com altura de cinco ou seis centenas de metros ou mais".

Muitas foram as proposições para a gênese do domo, entretanto somente com Montalvão \& Oliveira (1975) sua origem foi atribuída às intrusões toleíticas básicas, tendo sido eles os primeiros a denominarem a estrutura como braquianticlinal em forma de elipsóide com $30 \mathrm{~km}$ de comprimento e $20 \mathrm{~km}$ de largura.

Embora muitos trabalhos tenham sido desenvolvidos com o intuito de definir a origem do domo e sua deformação, ainda há necessidade de pesquisa neste sentido.

${ }^{1}$ Programa de Pós-Graduação do Departamento de Geologia da Universidade Federal do Paraná - UFPR, Curitiba (PR), Brasil.

${ }^{2}$ Departamento de Geologia da UFPR, Curitiba (PR), Brasil. E-mails: salamuni@ufpr.br, ferman@ufpr.br

*Autor correspondente 


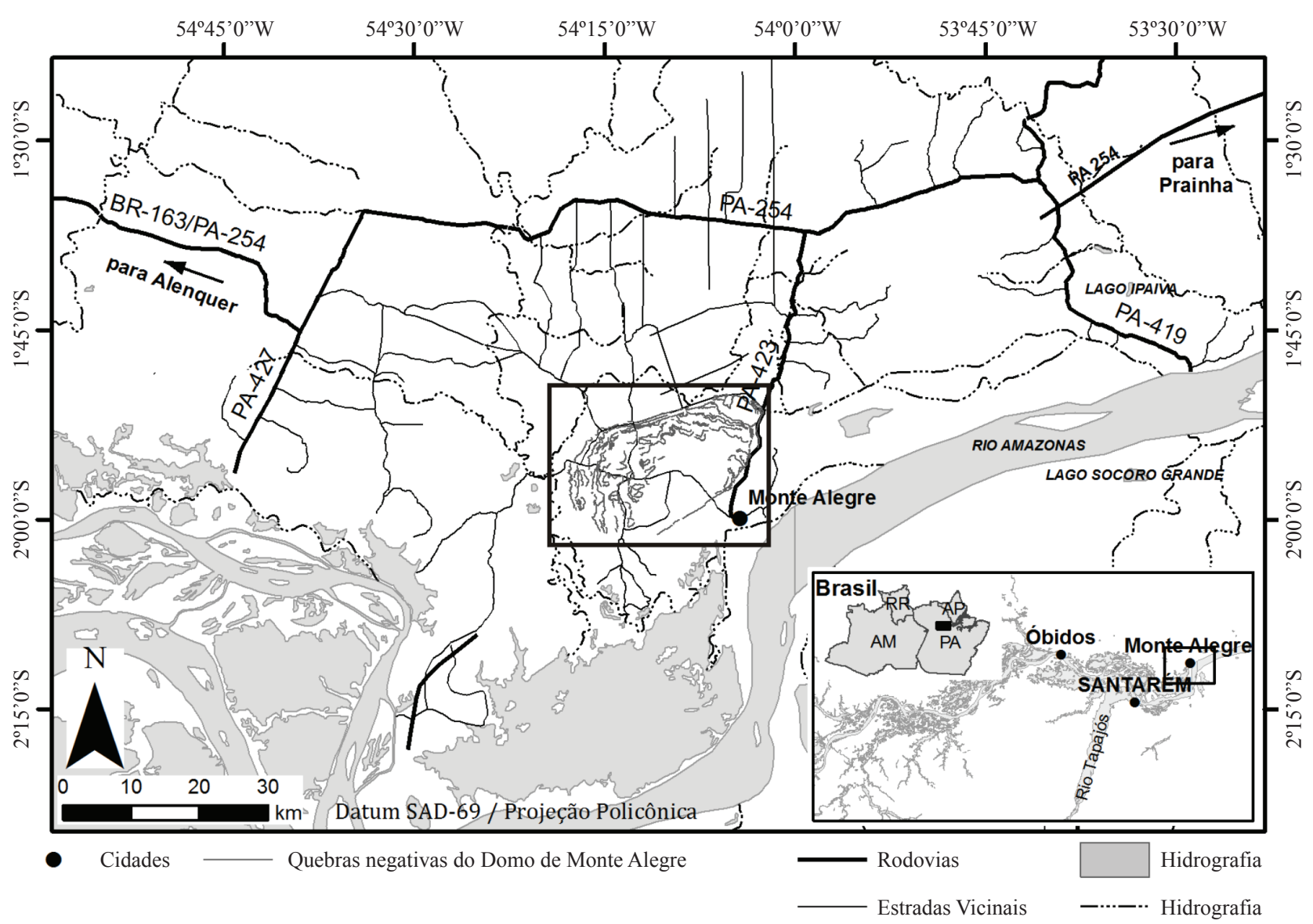

Figura 1-Localização e acesso à área do Domo de Monte Alegre, no estado do Pará. O Domo de Monte Alegre, inserido no retângulo ao centro da figura, encontra-se a norte da cidade e, neste mapa, está representado pelas quebras negativas (Figueira 2011).

O domo de Monte Alegre é caracterizado pela ocorrência de rochas sedimentares dos Grupos Urupadi, Curuá e Tapajós, com idades do Devoniano ao Carbonífero, limitadas por falhas com rochas do Grupo Javari (Cretáceo/Terciário). Ele tem sido alvo de pesquisas de natureza minerária, estratigráfica e arqueológica. As rochas paleozoicas foram posteriormente seccionadas pelo magmatismo toleítico do evento Penatecaua de idade Eojurássica.

Pesquisas acerca de detalhes da deformação do domo de Monte Alegre e de rochas nele contida são escassas, havendo lacunas na caracterização tectônica dos eventos de deformação. Em função disto buscou-se realizar um levantamento de dados estruturais do registro das deformações em várias unidades estratigráficas que compõem o domo, em especial nas soleiras e diques do magmatismo Penatecaua que afloram na região. Nesta unidade observou-se, principalmente em afloramento de pedreira, que há uma importante deformação rúptil caracterizada por estruturas como falhas, estrias, steps, ocorrência de tectonitos e outras, que possibilitaram a análise e a interpretação das direções das paleotensões atuantes após o citado evento magmático.

MATERIAIS E MÉTODOS Ao longo do desenvolvimento do trabalho foi realizada ampla pesquisa bibliográfica a respeito da evolução geológica do domo de Monte Alegre. Dentre os trabalhos consultados, destacam-se os de Hartt (1870), Issler (1974), Montalvão \& Oliveira (1975), Pastana et al. (1978), Pastana (1999), Anjos et al. (2003) e Almeida \& Pinheiro (2007), que são mais relevantes ao tema proposto. Referência deve ser dada também a alguns trabalhos clássicos de geologia, que, entre outros assuntos, abordam aspectos de deformação e evolução tectono-estratigráfica da Bacia do Amazonas, tais como os de Lange (1967), Caputo et al. (1971, 1972), Caputo (1984), Rezende \& Brito (1973), Cunha et al. (1994), Sena Costa \& Hasui (2000) e Vasquez et al. (2008). Referências sobre aspectos neotectônicos e geofísicos podem ser encontradas, respectivamente, 
nos trabalhos de Sena Costa et al. (1996), e análise de sensores remotos em Miranda (1983).

Em relação aos trabalhos de campo, os levantamentos estruturais consistiram em obter dados relativos à geometria das fraturas, a seu espaçamento, às medidas estruturais de juntas e falhas (planos/estrias) e à identificação de indicadores cinemáticos. Foram também caracterizados, quando possível, materiais de preenchimento destas fraturas, tanto aqueles precipitados quanto os gerados em zonas de gouge. Procurou-se hierarquizar cronologicamente as estruturas identificadas.

As informações adquiridas em campo foram organizadas em tabelas, para a geração de diagramas estruturais e, posteriormente, análise estrutural sistemática (geométrica e cinemática), bem como direções de paleotensões.

Para a análise estrutural propriamente dita, os dados foram tratados em programas de análises estereográficas. Inicialmente utilizou-se o StereoNet, pelo qual foram gerados diagramas de rosetas para os conjuntos de dados estruturais rúpteis. Os dados das juntas foram agrupados em diagramas de contornos dos pólos e estes foram sobrepostos às direções em forma de rosetas.

Por convenção, na pesquisa procedida, as falhas foram individualizadas por apresentarem, além do plano de descontinuidade, estrias de atritos e indicadores cinemáticos, ou seja, aqueles que permitem o reconhecimento do sentido de movimento, tais como degraus (steps) e sulcos. Posteriormente, para calcular os campos de tensão, foi utilizado um programa livre (freeware) denominado Sigmas, desenvolvido por Freitas (2005), que permite o cálculo dos campos de tensão a partir de dados de falhas. Estes cálculos têm por base o modelo Mohr-Coulomb, que se refere à indicação de uma componente de deformação

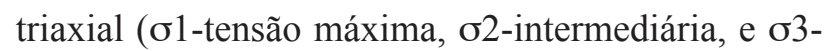
tensão mínima), relacionada ao plano de falha (Price \& Cosgrove 1990). Neste, os eixos o1 e o3 estão inseridos em um plano auxiliar que contém o vetor referente ao movimento (estria) bem como o normal ao plano de falha (polo do plano de falha).

No programa Sigmas foram inseridos os dados de planos, estrias de falha e também o sentido de movimento (ou cinemática), se normal, reverso, dextrógiro ou sinistrógiro, dos blocos falhados. Este programa não apenas permite calcular a localização dos pontos que representam, estatisticamente, os campos de tensão, como também os projeta além da guirlanda do plano de falha e a estria. Os dados das paleotensões foram incorporados na planilha e correlacionados aos dados de fraturas obtidos em campo. Inicialmente todos os pontos foram agrupados em diagramas com os respectivos valores de $\sigma 1$, $\sigma 2$ e $\sigma 3$. O objetivo foi separar as paleotensões em eventos correlatos, responsáveis pela deformação da estrutura dômica. Com base nesta subdivisão foram definidos os diferentes eventos registrados nas falhas na região do domo.

De forma complementar utilizou-se, também, um segundo programa livre para as análises estruturais, denominado WinTensor, desenvolvido por Damien Delvaux, do Departamento de Geologia e Mineralogia do Royal Museum for Central Africa. $O$ formato de entrada dos dados neste programa difere um pouco do programa Sigmas, posto que devem ser representados com os seguintes detalhes: quanto aos formatos, podem variar em dip-angle/dip-direction, dip-direction/dip-angle, strike $\left(0-180^{\circ}\right) /$ dip-angle (Norte, Leste, Sul ou Oeste) e strike $\left(0-360^{\circ}\right) /$ dip-angle $\left(\right.$ dip-dir $=$ srtike $\left.+90^{\circ}\right)$; quanto às estruturas, devem ser definidas pelo plano de falha com estria, par conjugado, plano de cisalhamento com fratura de tensão, fratura, acamamento, foliação, ou tipo da fratura, incluindo pluma, junta, veio, dique, compressão com movimento de cisalhamento, plano de acamamento, plano de foliação; quanto ao nível de confiabilidade, classificando-se em certo, provável, suposto ou desconhecido.

A segunda análise teve o objetivo de constatar a acurácia dos resultados obtidos pelo programa Sigmas (Freitas, 2005) e também calcular as regiões compressivas e distensivas pelo método dos diedros retos de Angelier \& Mechler (1977). Um recurso adicional do programa WinTensor é a visualização da direção dos planos por rosetas bem como a direção dos mergulhos dos planos de fraturas. As estrias são representadas pela direção dos mergulhos e azimute.

\section{CONTEXTO GEOLÓGICO REGIONAL O em-} pilhamento estratigráfico observado no domo de Monte Alegre (Fig. 2) confirma a estratigrafia apresentada por Cunha et al. (1994) para a Bacia do Amazonas, subdivida em quatro sequências separadas por discordâncias: Ordoviciana-Devoniana, que reúne os sedimentos clásticos marinhos do Grupo Trombetas e está parcialmente truncada pela discordância decorrente da Orogenia Caledoniana; Devoniana-Carbonífera, correspondendo aos 


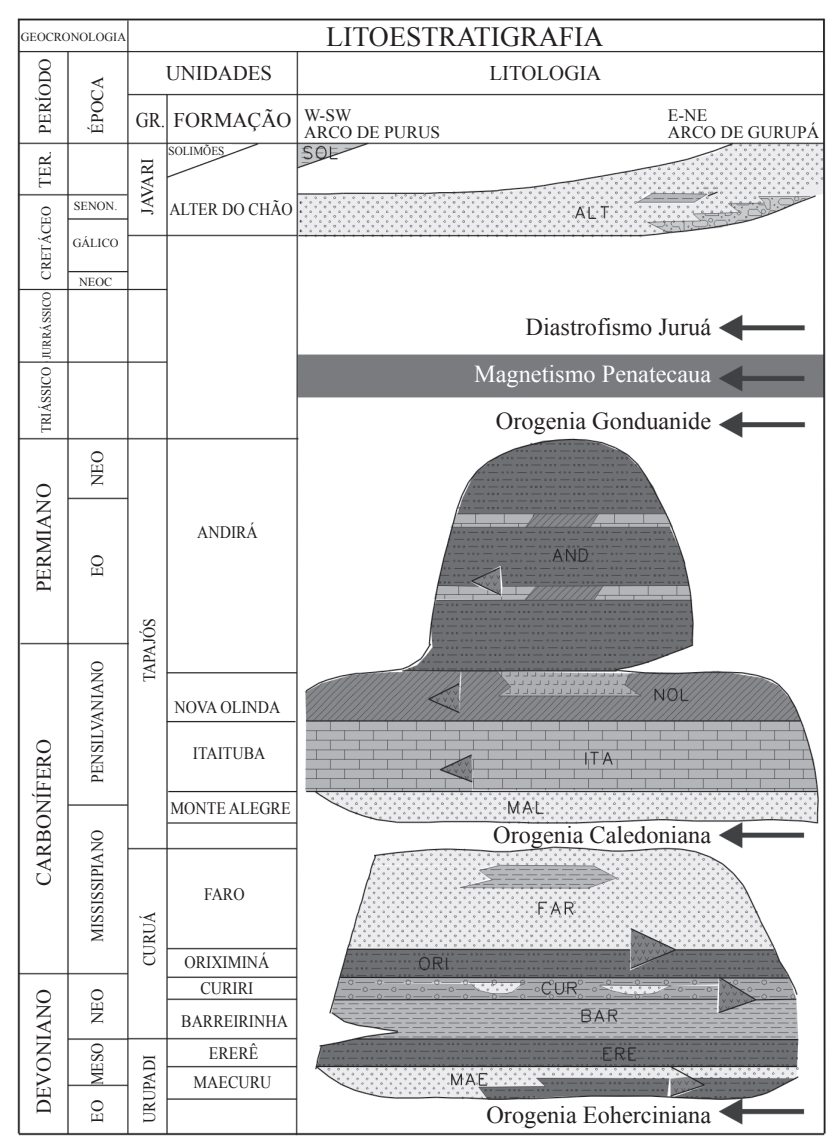

Figura 2 - Parte da Carta Estratigráfica da Bacia do Amazonas correspondente às unidades estratigráficas presentes no Domo de Monte Alegre, Pará. Modificado de Cunha et al. (1994). sedimentos clásticos flúvio-deltáicos e neríticos dos grupos Urupadi e Curuá, e possuindo topo marcado pela discordância relacionada à Orogenia Eo-Herciniana; Permo-Carbonífera, formada pelos clásticos, carbonatos e evaporitos continentais e de ambiente marinho restrito do Grupo Tapajós, e profundamente cortada pela discordância resultante da Orogenia Gonduanide e do Diastrofismo Juruá; e Cretáceo-Terciária, composta pelos clásticos flúvio-lacustres do Grupo Javari ocupou os espaços criados pela atividade da Orogenia Andina.

As rochas descritas no domo correspondem, na base da coluna, a arenitos com marcas onduladas e estratificação plano-paralela de ambientes litorâneos da Formação Manacapuru, que estão sobrepostas aos siltitos neríticos e deltaicos da Formação Ererê. Entre esta formação e a subsequente, um pequeno pulso regressivo resultou na deposição dos folhelhos negros da Formação Barreirinha. Para o topo desta unidade foram cartografados siltitos micáceos e siltitos com grãos angulosos que podem estar associados ao ambiente glacial proposto por Caputo (1984) para a Formação Curiri.

Os arenitos finos a médios da Formação Oriximiná associam-se à ambiente fluvial regressivo e estão cobertos por siltitos amarelados com estratificações cruzadas tabulares de pequeno porte,

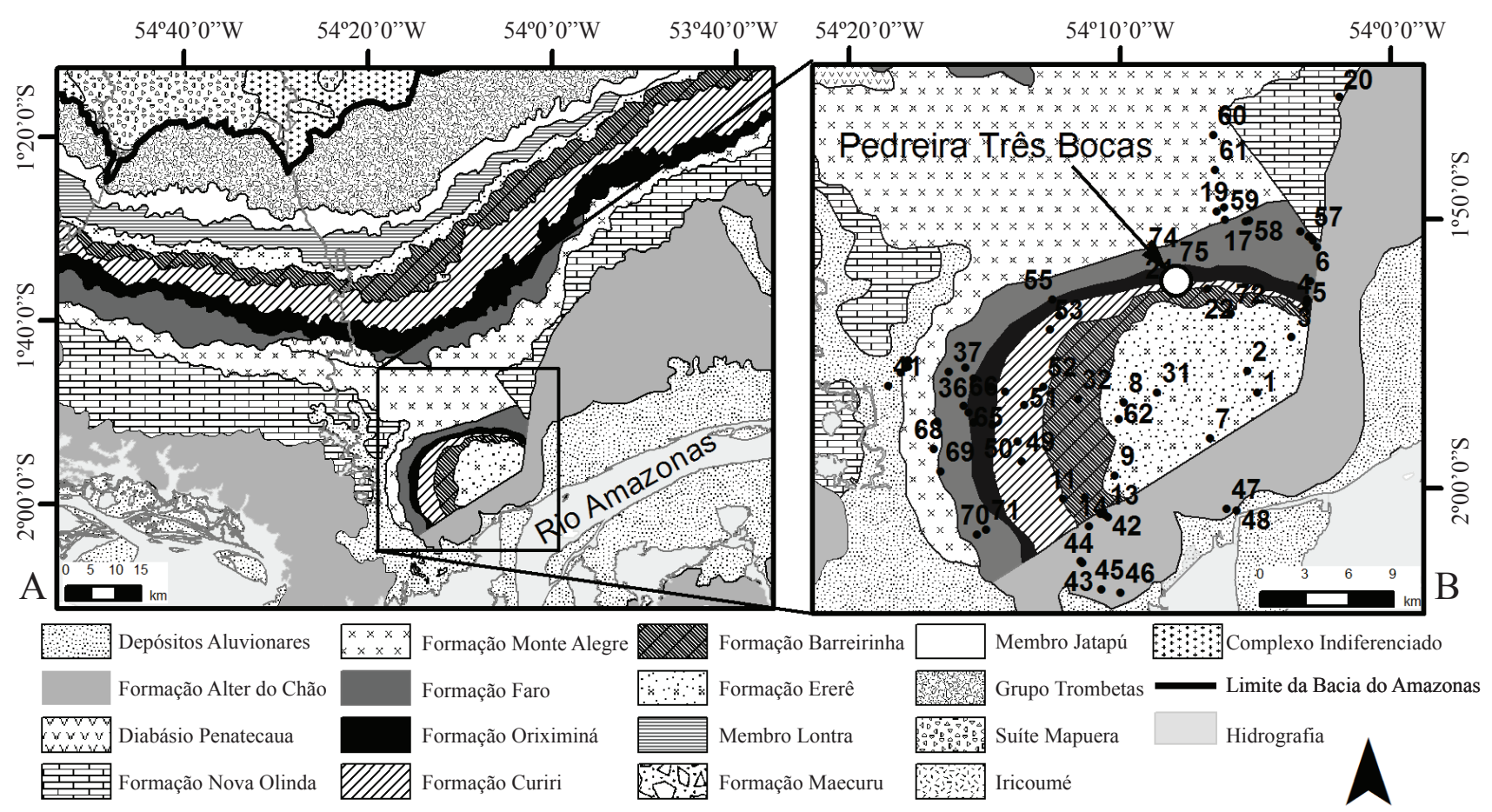

Figura 3 - (A) Mapa Geológico da região do domo do Monte Alegre; (B) Detalhe do domo com os pontos mapeados. Fonte: CPRM (2008). 

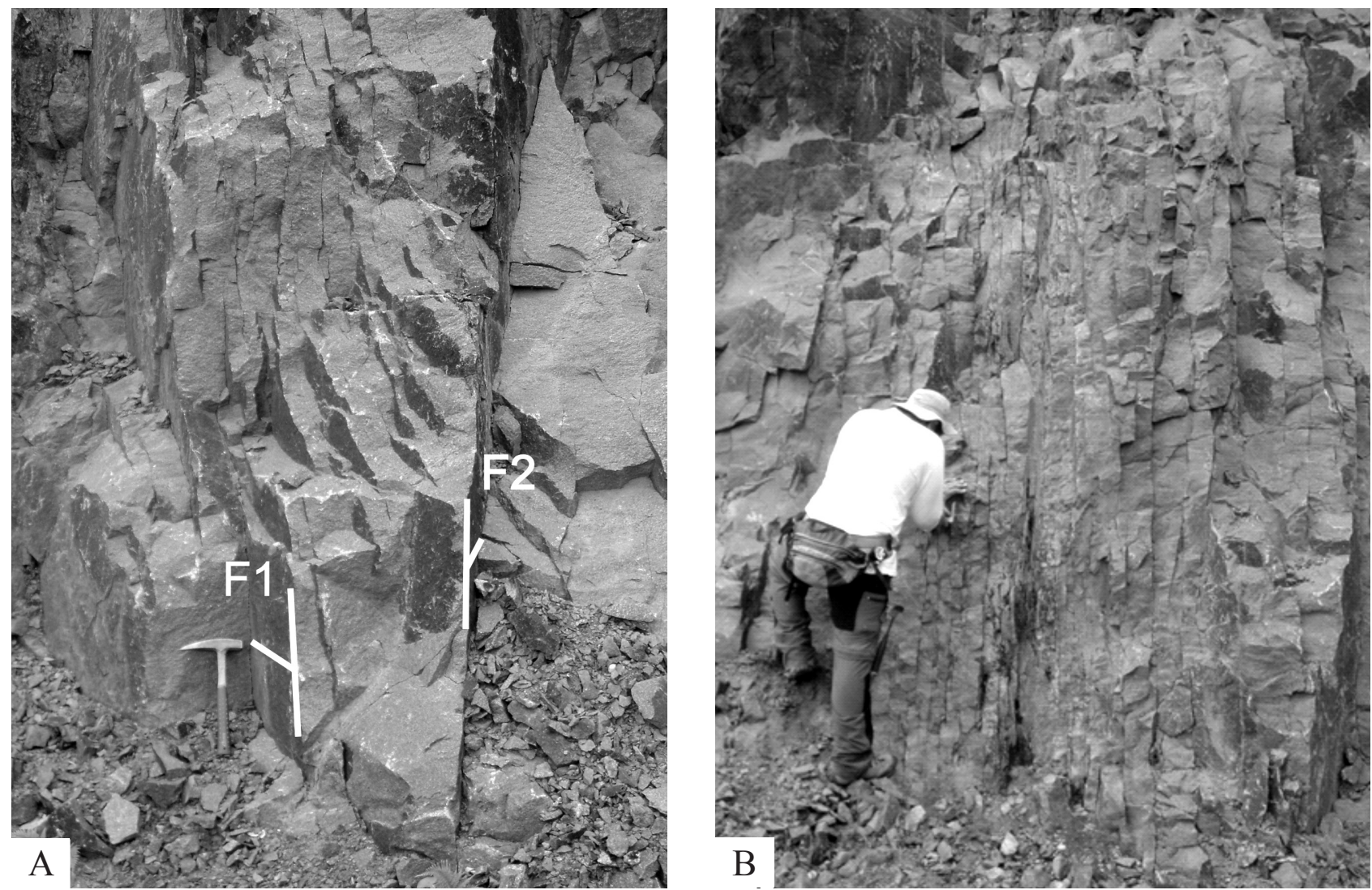

Figura 4 - (A) Zonas de cisalhamento simples rúptil dos sistemas de fraturas 1 (F1) e 2 (F2) que se intersectam, identificadas nas rochas da pedreira Três Bocas, no ponto MA-21, com uma coordenada de atitude 54 $\left.7^{\prime} 46^{\prime \prime} / 1^{\circ} 52^{\prime} 13^{\prime \prime}\right)$; (B) Zona de cisalhamento rúptil do sistema F1, banda com intensa cataclase subvertical.

provavelmente flúvio-deltáico da Formação Faro. Mais novo que este conjunto sedimentar, há um novo ciclo transgressivo-regressivo associado a mudanças de clima frio para quente. Este ciclo se inicia com arenitos eólicos com variações granulométricas desde os finos até os sedimentos conglomeráticos. Esta unidade grada em direção ao topo para marinho raso, onde são sobrepostas por rochas calcárias da Formação Itaituba/Nova Olinda. Na seção cartografada não foram identificados arenitos da Formação Andirá, provavelmente erodidos.

Por fim, cortando as seções sedimentares estratificadas estão as rochas magmáticas do evento Penatecaua, intrudidas tanto na forma de diques quanto de sills. Dutra (2005) menciona que tais rochas representam o registro de um extenso magmatismo, no norte do Brasil, inseridas na Província Magmática Atlântico Central. Esta província é composta por diques, soleiras e derrames de composição basáltica com idade de $190 \pm 20$ ma (Mizusaki et al. 1992).

De modo geral, nos afloramentos visitados verificou-se a ocorrência de diabásio cinza escuro de textura afanítica e gabros acinzentados, com textura fanerítica inequigranular a equigranular porfirítica, composta por piroxênio, plagioclásio e biotita, eventualmente olivinas. Há também porções com textura glomeroporfirítica de piroxênio contornados por massa fanerítica grossa, com cristais ripiformes de plagioclásio formando textura ofítica. Trata-se de rochas com estruturas originais isotrópicas, dada pela homogeneidade na constituição e distribuição mineralógica. Eventualmente observa-se, no afloramento, diáclases resultantes de disjunção colunar, porém, em geral, o aspecto é maciço.

Em função da abertura relativamente recente de pedreira (Pedreira Três Bocas) com coordenada $54^{\circ} 7^{\prime} 46^{\prime \prime} / 1^{\circ} 52^{\prime} 13$ " em destaque na Fig. 3, no afloramento de uma soleira, cujo material é utilizado como agregado para a construção civil, foi possível um bom detalhamento não só da rocha exposta, mas também das estruturas primárias e secundárias.

\section{GEOLOGIA ESTRUTURAL E TECTÔNICA}

Em função da homogeneidade reológica dos gabros Penatecaua, e também pelo fato deles terem sido originados no mesmo período de ocorrência (Jurássico), 
inferiu-se que a estruturação rúptil superimposta a este corpo rígido pode ter ocorrido a partir do Eo-Cretáceo.

Do ponto de vista dos modelos de fraturas de Anderson (1951) e Riedel (1929), o ideal é realizar a análise estrutural num maciço homogêneo para se definir um quadro tectônico. Tal princípio foi respeitado e, desta forma, realizou-se a análise geométrica e cinemática das estruturas que resultam de sua deformação, geradas nos eventos tectônicos aqui denominados F1 e F2, que são cronologicamente sucessivos, todavia não progressivos. Em ambos os sistemas, os planos de fraturas gerados possuem mergulhos
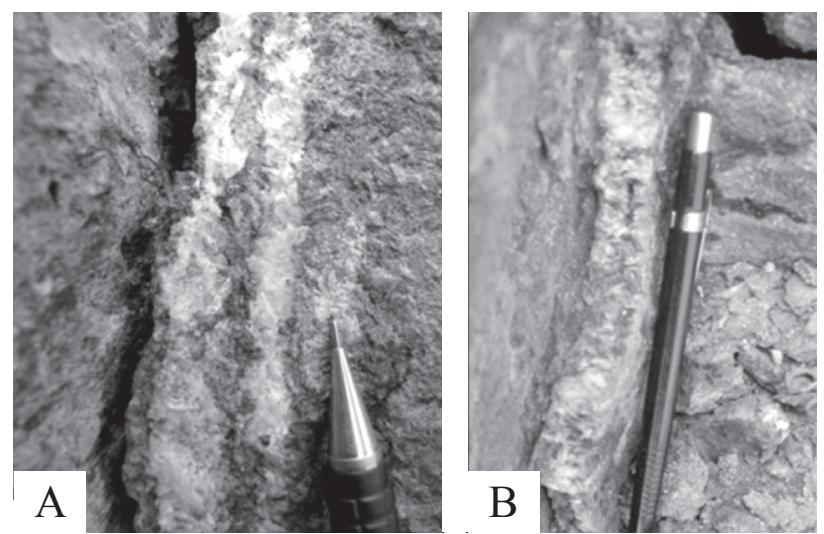

Figura 5 - (A) Falhas nas rochas igneas da pedreira Três Bocas que estão preenchidas por quartzo do sistema de fraturas 2; (B) Crescimento fibroso, de quartzo perpendicular à zona de falha. empinados e, não raras vezes verticais, correspondendo a processos de cisalhamento simples rúptil (Fig. 4A).

A geometria da deformação do sistema de fraturas F1 (Figueira, 2011) caracteriza um quadro de cisalhamento rúptil relativamente complexo, representado por um sistema de falhas de características mais ou menos semelhantes entre si. Neste sistema foram identificadas descontinuidades estruturais planares, lisas, sistemáticas, densas, métricas a decamétricas, em geral fechadas, empinadas a verticais. As direções médias encontradas foram N10W e N80W, sendo estas as principais direções das famílias de falhas. O sistema de falhas frequentemente é responsável por intensa cataclase e cominuição das rochas afetada, como mostra a Fig. 4. Há, também, outras direções importantes neste mesmo sistema, como é o caso da N45W.

O sistema de fraturas de F2 é representado por falhas planares, lisas a rugosas, também métricas a decamétricas, porém menos densas que o primeiro sistema. Em geral são abertas e, em muitos casos, estão preenchidas por minerais euédricos de calcita, calcopirita e quartzo, cujo crescimento é fibroso orientado de forma perpendicular ao plano da fratura (Figs. 5 e 6). A direção preferencial deste sistema está em torno de N20E, havendo fraturas conjugadas subsidiárias de direção N50E.

Os dados foram suficientes para que se fizessem análises geométricas e cinemáticas da estruturação
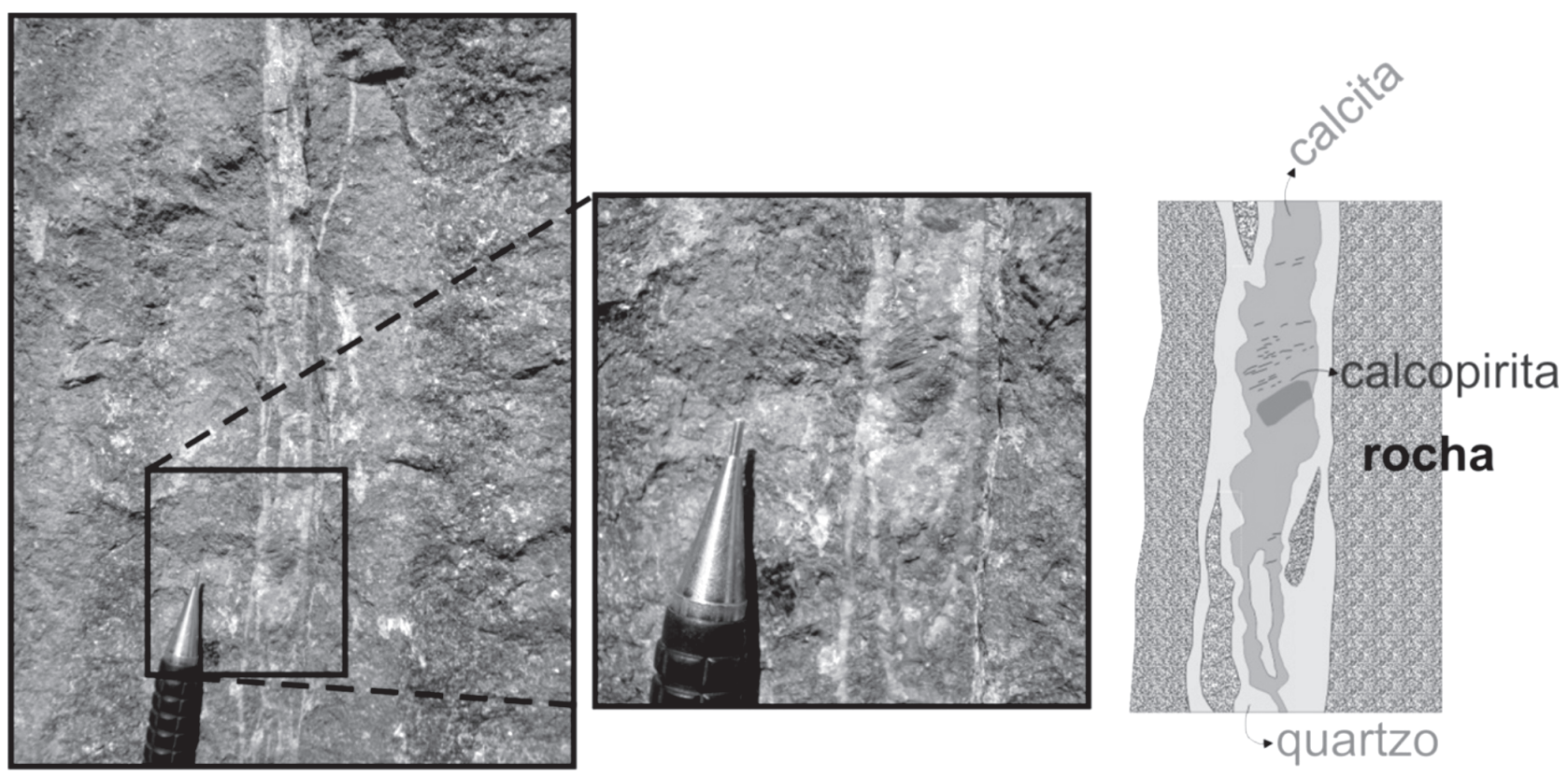

Figura 6 - Fraturas com preenchimento de quartzo, calcitas em fibras e calco pirita euédrica. 

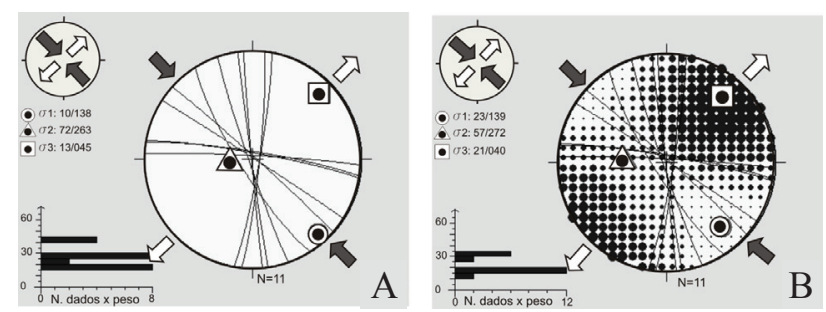

Figura 7- (A) Diagrama ciclográfico confeccionado com dados do sistema de fraturas 1; (B) Campos de paleotensões obtidos no WinTensor, por meio do método dos diedros retos.
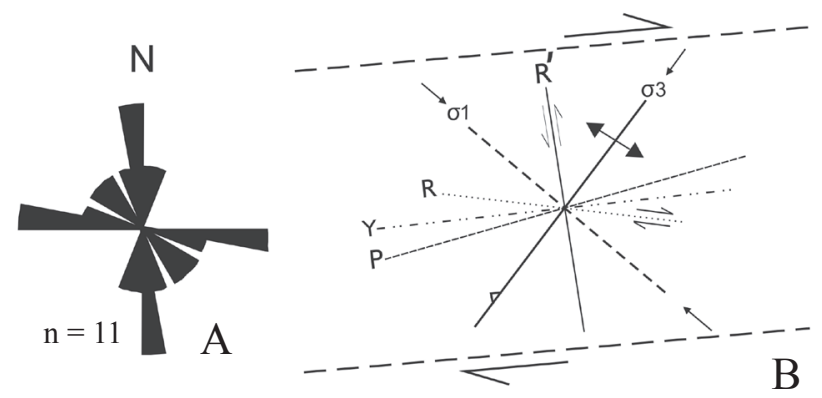

Figura 8 - (A) Diagrama de roseta confeccionado com dados do sistema de fraturas 1 (F1), o qual mostra a direção das fraturas cisalhantes; (B) posição do modelo de Riedel nas rochas igneas na região do domo de Monte Alegre referente ao sistema de deformação F1, com o campo de paleotensão máximo $(\sigma l)$ de direção Noroeste-Sudeste e direção principal das estruturas (Y) a N85E.

que deforma o maciço, possibilitando a interpretação da direção da paleotensão $\sigma 1 \mathrm{e}$, consequentemente, das paleotensões $\sigma 2$ e $\sigma 3$ para cada uma das fases determinadas (F1 e F2).

A análise cinemática realizada pelo programa WinTensor exigiu a existência de dados estruturais conclusivos sobre a direção e o sentido de movimento das falhas locais (Fig. 7).

Após sucessivas análises a partir da seleção de dados e informações caso a caso; determinou-se que para o sistema de fraturas da fase $\mathrm{F} 1$ as direções dos planos de falha $\mathrm{T}$ possuem direção N45W e correspondem ao vetor de paleotensão máxima, como mostram o diagrama e o modelo da Fig. 8. As falhas N40W foram definidas como dextrógiras, enquanto as falhas N-S e N10-30W são sinistrógiras. Igualmente ocorre uma falha inversa a N20W e as restantes são falhas normais com direção N10W.

Para o sistema de fraturas F2, cujo regime é também transcorrente, a paleotensão máxima o1 está na direção N45E, portanto diferente do sistema anterior. Em afloramento, as fraturas de tensão
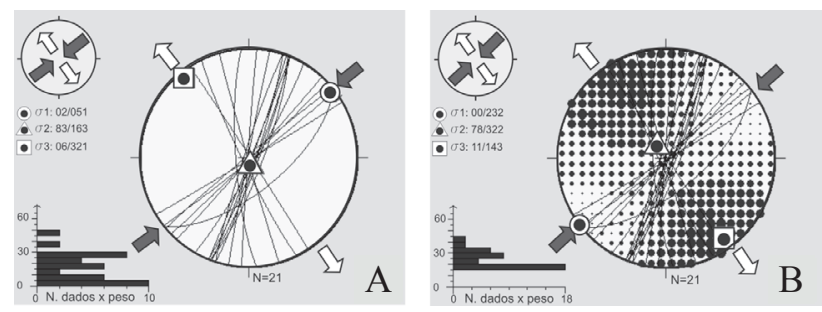

Figura 9- (A) Diagrama ciclográfico confeccionado com dados do sistema de fraturas 2; (B) Campos de paleotensões obtidos no WinTensor, por meio do método dos diedros retos.
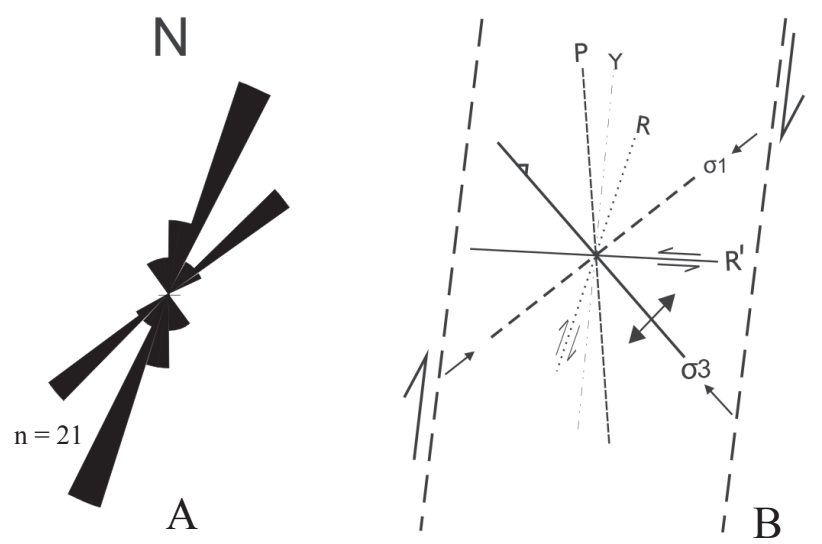

Figura 10 - (A) Diagrama de roseta confeccionado com dados do sistema de fraturas 2 (F2), mostrando a direção das fraturas cisalhantes; (B) Modelo de Riedel nas rochas ígneas na região do domo de Monte Alegre relativo ao sistema F2, com a direção de compressão máxima (ol) a N45E e direção principal das estruturas (Y) a N10E.

T são em geral abertas e quase sempre preenchidas por calcita. O campo de paleotensão $\sigma 2$ continua essencialmente na vertical e a tensão $\sigma 3$, por sua vez, está aplicada aproximadamente a N40W (Fig. 9). O sistema, como um todo, é caracterizado por falhas dextrógiras, facilmente identificadas em campo devido à presença de estrias e degraus (steps). As principais falhas regionais são $\mathrm{N} 30 \mathrm{E}$, enquanto as direções N-S e NW-SE ocorrem com menor frequência, como pode ser visto na Fig. 10A. A Fig. 10B mostra as descontinuidades tectônicas no modelo de Riedel, sendo a direção N20-30E ajustada aos pla$\operatorname{nos} \mathrm{R}$ e à direção N10E ao plano Y (principal de cisalhamento).

Algumas dobras foram observadas em rochas da Formação Ererê, especificamente na borda sul (ponto 07) do domo, formada por siltitos e argilitos acamadados em sets decimétricos a métricos (Figs. 11A e B). Em geral, são reclinadas ou normais, suaves a abertas, com eixos caindo para o quadrante 

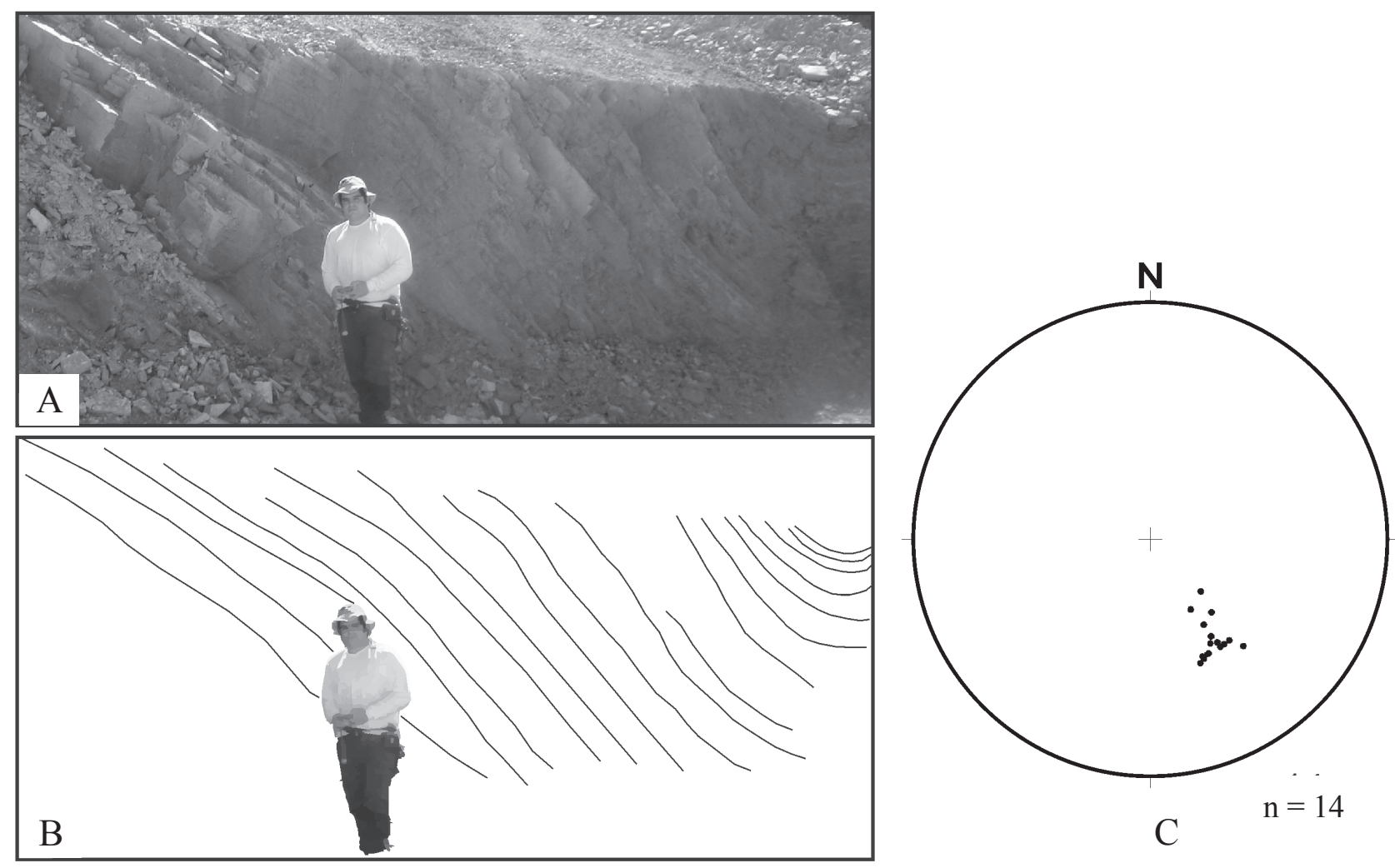

Figura 11 - (A) e (B) Dobras reclinadas suaves a abertas em siltitos e argilitos da Formação Ererê,; (C) Diagrama de Schmidt (hemisfério inferior), com os eixos de dobras posicionados no quadrante SE, compativel com o modelo teórico de fraturas da fase 2 (sistema de fraturas 2).
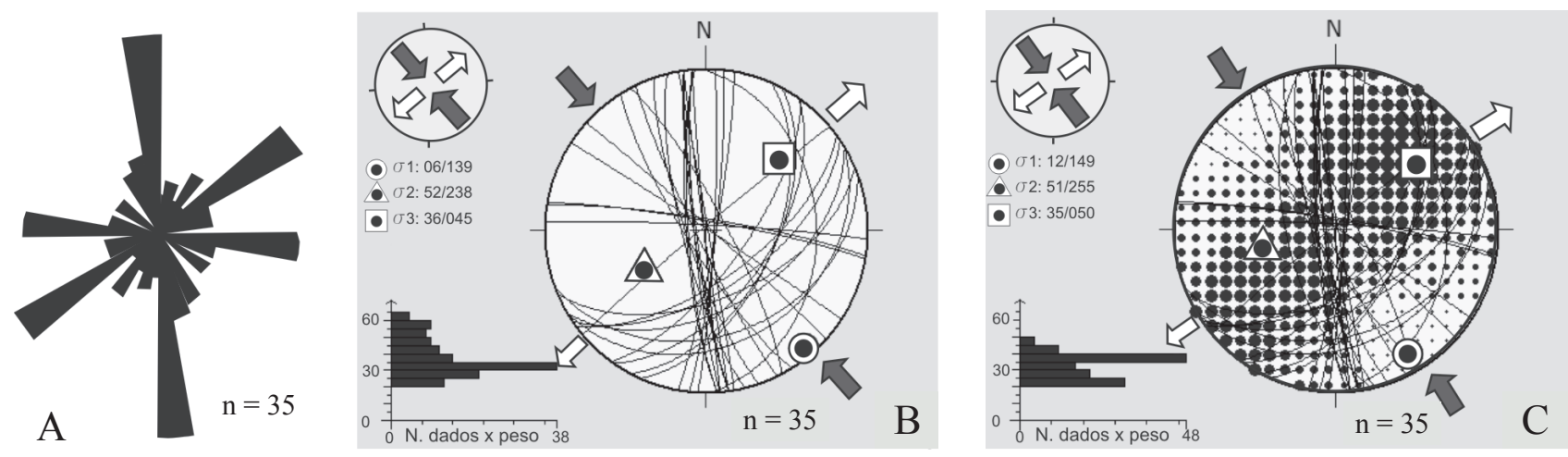

Figura 12 - (A) Roseta das principais direções das falhas; (B) Diagrama com campo de tensão; (C) Diedros retos.

SE. Não são observadas em todos os afloramentos da formação. A importância estrutural se dá pelo fato de que seu posicionamento geométrico reforça o modelo de fraturamento aplicado à fase $\mathrm{F} 2$, visto que os eixos (Fig. 11C) são coincidentes com o que se espera no modelo teórico (Fig. 10B).

DISCUSSÃO Após o evento magmático Penatecaua, provocado pela Orogenia Gonduanide (Zalán 1991), a região de Monte Alegre, no Pará, foi afetada pelo menos por dois eventos tectônicos distintos. Eles deformaram, por meio de falhas e juntas bem definidas em zonas de cisalhamento rúptil, rochas magmáticas do Penatecaua, ou seja, gabros e diabásios intrudidos como sills e diques, respectivamente. Todavia, em suas encaixantes sedimentares, Formações Curiri e Barreirinha, as estruturas rúpteis são menos conspícuas e caracterizadas por fraturas irregulares e anastomosadas, não tendo sido observados indicadores cinemáticos associados nos planos de descontinuidade.

A primeira fase de deformação está associada às falhas do sistema $\mathrm{F}$ 1, com campos de paleotensão máximo 


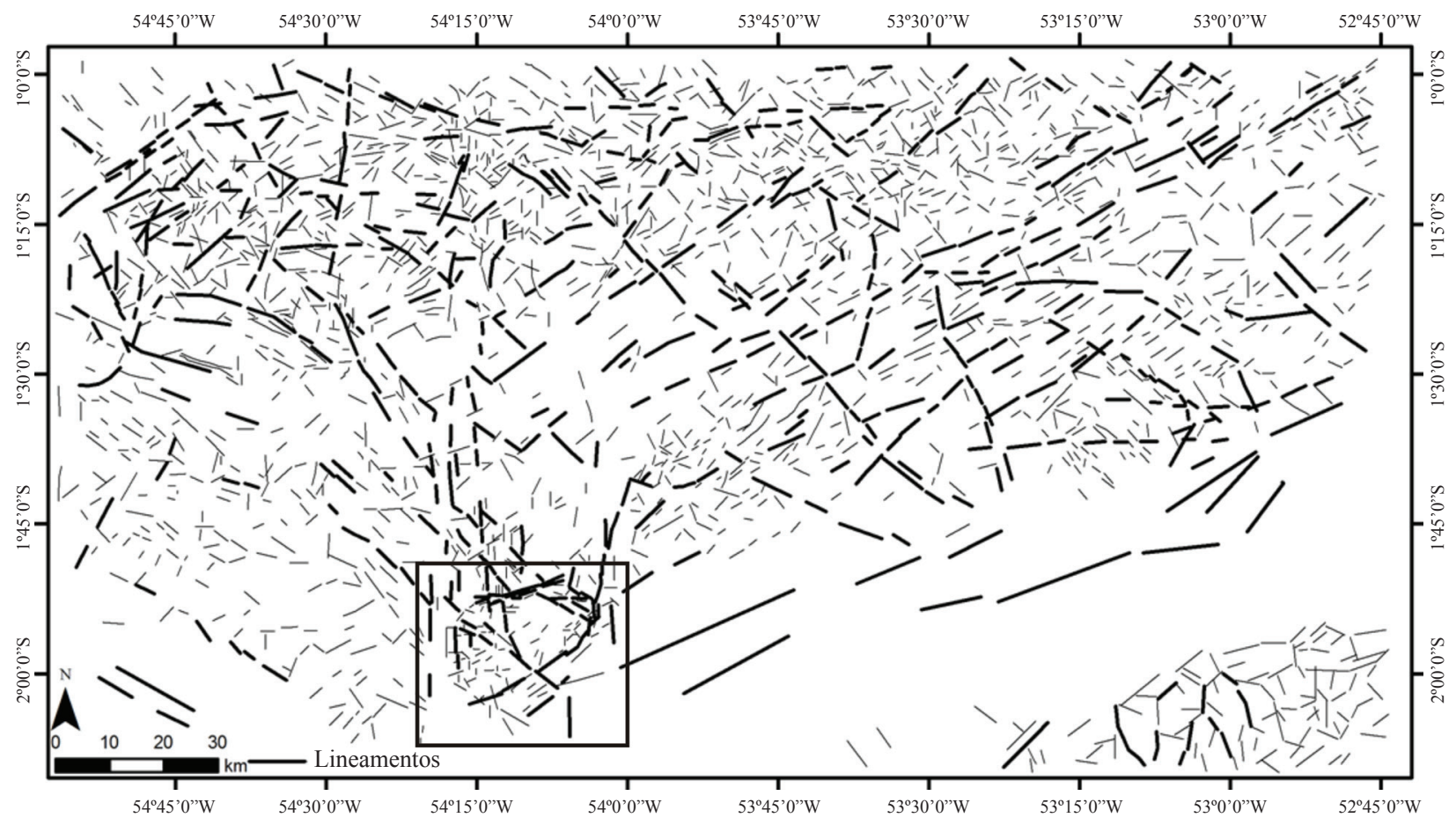

Figura 13 - Feições lineares obtidas do modelo Shuttle Radar Topography Mission (SRTM) da região de Monte Alegre e seu entorno, onde é possível verificar que as direções N70E são mais evidentes na interpretação regional.

na direção NW-SE relacionados ao Diastrofismo Juruá, já descrito por diversos autores (Caputo 1984, Szatmari 1983, Campos \& Teixeira 1988). O diastrofismo, também chamado Tectônica Juruá, e bem definido na Bacia do Solimões, é caracterizado por esforço compressivo nos quadrantes NW-SE, que criou zona de cisalhamento dextrógira na direção N75E (Caputo 1985). No domo de Monte Alegre, este evento de deformação teria sido responsável por diversas estruturas, como grandes falhas inversas mapeadas em campo de direções N70E, apresentadas nos diagramas estruturais confeccionados para fraturas das rochas entre Devoniano e Carbonífero da Fig 12; falhas transcorrentes sinistrógiras N-S, falhas transcorrentes dextrógiras NW-SE e algumas falhas normais $\mathrm{N} 80 \mathrm{~W}$, conforme demonstrado anteriormente, compatíveis com o modelo de Riedel confeccionado para fraturas do Penatecaua (Fig. 8).

Nas rochas da Formação Ererê, posicionadas na borda sul do domo (ponto 7 da Fig. 3) ocorrem falhas transcorrentes dextrógiras com componente oblíqua inversa, atitude média de N70E/60NW, cuja direção é comparável às traçadas em imagens aéreas e orbitais, que, por sua vez, revelam forte alinhamento estrutural (Fig. 13). Esta direção foi comparada à direção $\mathrm{Y}$ do modelo de Riedel (Fig. 8), assim como as falhas rúpteis inversas com direção N30E/60NW (ponto 6 da Fig. 3), igualmente compatíveis com o referido modelo.
As falhas que ocorrem no sistema da fase F1 com direção variável entre N65E a N25E devem ter sido provocadas pela mesma deformação que resultou em um conjunto de dobras assimétricas e falhas inversas, inclusive as com grandes rejeitos, que variam entre 500 e $1.000 \mathrm{~m}$, verificado em linhas sísmicas (Caputo 1984) e que constituem a deformação finita resultante do efeito compressivo do primeiro evento, que afetou o Magmatismo Penatecaua.

Já a segunda fase de deformação (F2) é uma possível resultante de evento de deformação maior, associado à compressão da placa Sul-americana em função do seu travamento pelas placas de Nazca e Cocos. As paleotensões máximas ( $\sigma 1)$ estão à N45E, assumindo esta direção devido a um provável jogo de blocos tectônicos que permitiu a partição da deformação em escala local. Neste caso, o o2 está aproximadamente na posição vertical. O modelo de fraturas (de Riedel, Fig. 10B) nas rochas ígneas na região do domo de Monte Alegre relativo ao sistema de fraturas F2 gera falhas transcorrentes com direções N20E e N45E de natureza dextrógira.

De acordo com Montalvão \& Oliveira (1975) e Pastana (1999), o domo de Monte Alegre é uma estrutura braquianticlinal originada a partir de intrusão plutônica ou hipoabissal de maciço básico, cuja manifestação em superfície é observada na sequência do Magmatismo 


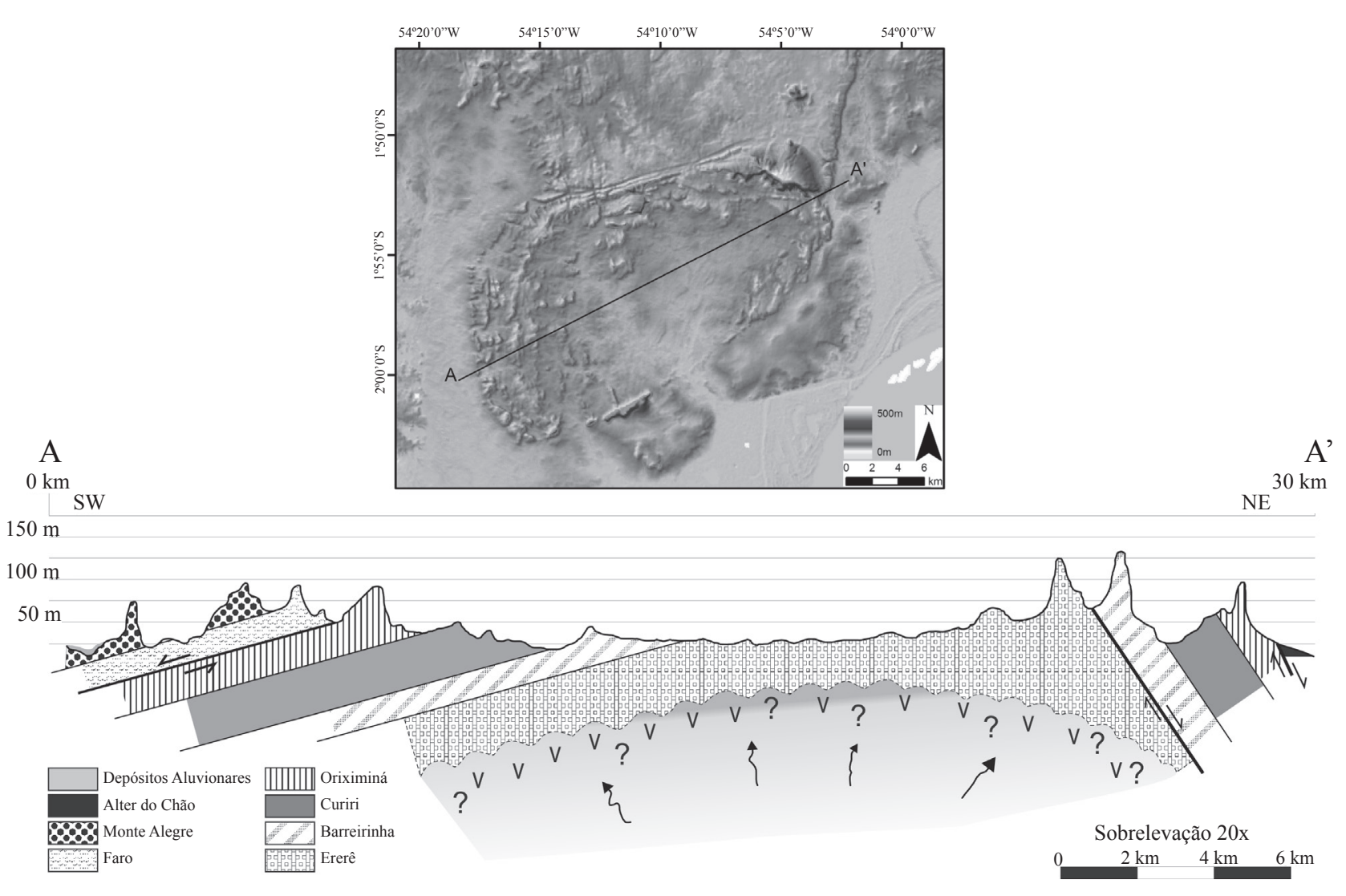

Figura 14 - Morfoestrutura dômica em Monte Alegre e seu perfil geológico, cuja origem tem sido interpretada por meio de processos magmáticos.

Penatecaua. O perfil geológico esquemático obtido pelas relações estratigráficas locais confirmam esta hipótese (Fig. 14).

As estruturas dômicas classicamente são circulares em superfície, com elementos morfoestruturais, em geral, centrífugos. No entanto, o domo em questão possui forma alongada na direção NE-SW, mostrando-se na forma elíptica ou elipsoidal na terceira dimensão em subsuperfície. Considerando as interpretações anteriores e a forma atual como resultado de uma deformação regional, conclui-se que o domo, como um maciço heterogêneo, foi deformado por um regime de cisalhamento simples ou puro. Elipses de deformação em grande escala têm sido discutidas na literatura (Passchier 1987, Marques \& Coelho 2001, Chardon 2003), no que tange seu ajuste a processos de cisalhamento simples (Figs. 15A e 16A).

Há de se considerar, no entanto, que formas elípticas geradas em cisalhamento simples são comuns em processos de deformação com certo grau de ductibilidade e, assim sendo, é possível interpretar a estrutura em análise como resultado de processo de deformação dúctil no início do pulso tectônico da F1. Todavia, mesmo considerando a forma elíptica atual do domo de Monte Alegre, os dados da estruturação nas rochas do magmatismo Penatecaua mostram que haveria a continuidade do pulso tectônico como cisalhamento simples rúptil ainda na primeira fase, visto que as direções teóricas da deformação do modelo de cisalhamento (Fig. 15A) estão bastante ajustadas aos dados geométricos e cinemáticos (Fig. 8B) e com a morfoestrutura estudada (Fig. 15B).

Por outro lado, é interessante notar que o comportamento dúctil pode conviver com o rúptil no mesmo maciço, desde que condições ou fatores reológicos assim o permitam, situação que acontece de fato no domo na comparação entre as rochas competentes do magmatismo Penatecaua e as sedimentares encaixantes.

A segunda fase é uma tectônica superimposta que provoca deformação na estrutura elipsoidal do domo (Fig. 16B). Também neste caso há ajuste entre a elipse teórica (Fig. 16A) e os dados de deformação mostrados no diagrama de paleotensão (Fig. 9). Deduzse assim, que o formato braquianticlinal possa ter advindo deste segundo processo de cisalhamento, também em função de um cisalhamento simples, derivado de paleotensão em direção quase ortogonal ao primeiro paleotensor. Por outro lado, também na segunda fase, admite-se que há convivência local, entre condições essencialmente rúpteis e aquelas de natureza mais dúcteis, 


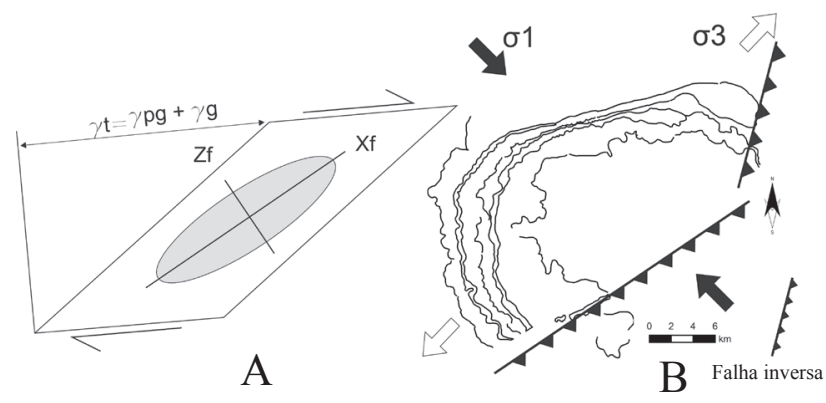

Figura 15 - (A) Modelo de deformação das fraturas do sistema de fraturas 1, utilizando-se a figura de Fiori (1997); (B) Representação esquemática atual da morfoestrutura do domo de Monte Alegre e eixos

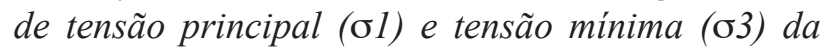
primeira fase de deformação pós-Magmatismo Penatecaua.

Zf: eixo da elipsoide; Xf: eixo da elipsoide; $\gamma t$ : deformação cisalhante finita: $\gamma p g$ : deformação sofrida pela encaixante; $\gamma g$ : deformação do corpo deformado.

o que, inclusive, possibilitou a geração de dobras locais, dependentes exclusivamente da natureza incompetente do litotipo afetado.

Tanto a F1 quanto a F2 foram caracterizadas por movimentos direcionais, em geral falhas de natureza puramente transcorrente e, secundariamente, com movimento levemente oblíquo conjugado. Tal caracterização foi possível graças à quantidade relativamente grande de planos de falha que apresentam estrias e steps (degraus) e permitem definir com precisão o sentido de movimento das falhas.

CONCLUSÃO O Magmatismo Penatecaua caracteriza-se na região enfocada por gabros acinzentados, com textura inequigranular fanerítica a inequigranular porfirítica, bem como por diabásio cinza escuro afanítico, os quais, respectivamente, ocorrem tanto como soleiras, na borda oeste e na região centro-norte da estrutura, onde se encontra a pedreira Três Bocas, quanto como diques, na borda sul do domo de Monte Alegre.

Tendo por base a estruturação das rochas básicas deste evento, foi possível concluir que há duas fases de deformação rúpteis-dúcteis a rúpteis: na primeira, em regime mais rúptil do que dúctil, ocorreu processo diastrófico, no qual predominam falhas fechadas ou com aberturas submilimétricas, com superfícies de ruptura mais lisas do que rugosas, planares e levemente anastomosadas, densas com extensão métrica a decamétrica. Nos planos há formação abundante de estrias de atrito e steps, os quais definem movimento sinistrógiro. Existe,
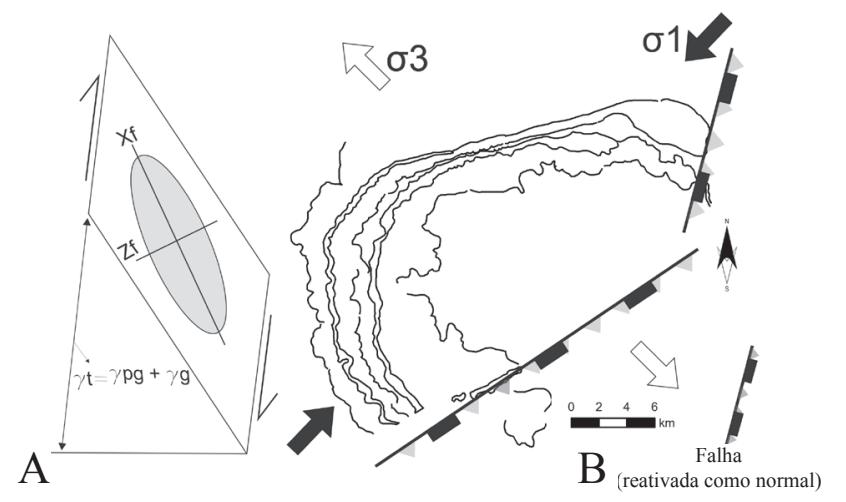

Figura 16 - (A) Modelo de deformação das fraturas do sistema de fraturas 2, utilizando-se a figura de Fiori (1997); (B) Representação esquemática atual da morfoestrutura do domo de Monte Alegre e eixos

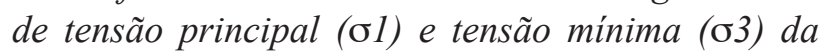
segunda fase de deformação pós-Magmatismo Penatecaua.

Zf: eixo da elipsoide; Xf: eixo da elipsoide; $\gamma t$ : deformação cisalhante finita: $\gamma p g$ : deformação sofrida pela encaixante; $\gamma g$ : deformação do corpo deformado.

de forma menos penetrativa, cataclase e brechas, além de esparsos gouges. E são frequentes as fraturas escalonadas sintéticas que interceptam as fraturas maiores e principais.

A segunda fase é representada igualmente por falhas e juntas abertas, pouco densas, com extensões métricas, superfícies de ruptura rugosas, planares, preenchidas com calcita pouco fibrosa e, por vezes, clastos de calcopirita. As estrias de atrito e steps em geral marcam movimentos dextrógiros. Pouca cataclase está associada a este evento, porém nos veios de preenchimento é possível observar pequenas brechas.

Ambos os sistemas foram gerados por cisalhamento simples e podem ser facilmente ajustados ao modelo de fraturas utilizado, no caso o de Riedel, mas não devem ser considerados progressivos entre si, apenas sucessivos, visto que há importante mudança no ângulo de incidência do eixo de paleotensão principal ( $\sigma 1)$, calculado na posição N139/23 (ou NE-SW) no caso da F1 e na posição N232/01 (ou NW-SE) no caso da F2. Tais eventos de deformação ocorreram no máximo após o Triássico, podendo eventualmente ter acontecido - ou pelo menos reativado — após o Cretáceo, caso a fase 1 seja associada à tectônica de compressão do Diastrofismo (ou Tectônica) Juruá, descrita por Szatmari (1983) e Caputo (1984).

A deformação dos gabros do Penatecaua, cuja composição e isotropia estrutural é propícia ao 
aumento da competência reológica, induz à conclusão de que todo o domo com seu conteúdo sedimentar mais incompetente foi deformado, passando de uma geometria esférica, ou circular em superfície, para uma elipsoidal, ou elíptica em superfície, ajustando-se ao modelo por cisalhamento simples nos primeiros momentos da deformação, sofrendo superposição em um segundo momento.

Tal superposição de eventos deformacionais devem ter sido a causa do domo ter adquirido seu aspecto geométrico final como uma braquiantiforma, como mencionado anteriormente por Montalvão $\&$ Oliveira (1975), e que certamente alterou seus aspectos geomorfológicos, propiciando dissecação peculiar no que tange à sua morfoestrutura final. Dobras em litotipos menos competentes, como siltitos e argilitos, mostram que a convivência entre um estilo de deformação finita mais rúptil com um mais dúctil foi factível no presente caso em função de importantes fatores reológicos distintos entre os diversos litotipos do domo de Monte Alegre.

Foi possível verificar que a atual estrutura elíptica do domo, como resultado da deformação finita das duas fases de deformação (F1 e F2), está correlacionada a regimes tectônicos regionais anteriormente descritos, tais como o Diastrofismo Juruá.

AGRADECIMENTOS Ao apoio financeiro da Petrobras, pela concessão de bolsa de pesquisa, ao Laboratório de Análise de Bacias e Petrofísica (LABAP), ao Projeto Caracterização TectonoEstrutural da Bacia do Amazonas (CATEA) e ao Prof. Dr. Elvo Fassbinder, pela leitura crítica e sugestões ao texto e pelo incentivo aos companheiros.

\section{Referências}

Almeida C. \& Pinheiro R.V.L. 2007. O papel das falhas na história tectônica do Domo de Monte Alegre, Bacia do Médio Amazonas, PA. In: $4^{\circ}$ PDPETRO. Campinas, Atas, p. 1-8

Anderson E.M. 1951. The dynamics of faulting. 2 ed. Edinburgh, Oliver \& Boyd, 206 p.

Angelier J. \& Mechler P. 1977. Sur une méthode graphique de recherché des contraints principales également utilizable en tectonique et en séismologie: la méthode des dièdres droits. Bulletin de la Societé Géologique de France, 7:1309-1318.

Anjos G.C., Lopes E.C.S., Villas R.N. 2003. Estudo geoquímico de águas da região da braquianticlinal de Monte Alegre (PA) com ênfase nas fontes termais. Geochimica Brasiliensis, 17(2):91-105.

Campos J.N.P. \& Teixeira L.B. 1988. Estilos tectônicos da Bacia do Amazonas. In: Congresso Brasileiro de Geologia, 35, Belém, Anais, v. 5, p. 2161-2172.

Caputo M.V., Rodrigues R., Vasconcelos D.N.N. 1971. Litoestratigrafia da Bacia do Amazonas. Belém, PETROBRAS/RENOR, 641-A, 92 p.

Caputo M.V., Rodrigues R., Vasconcelos D.N.N. 1972. Nomenclatura estratigráfica da Bacia do Amazonas. In: Congresso Brasileiro de Geologia, 26, Belém, Anais, v. 3, p. 35-46.

Caputo M.V. 1984. Stratigraphy, tectonics, paleoclimatology and paleogeography of northern basins of Brazil. Tese de Doutorado, Universidade da Califórnia, Santa Barbara, 583 p.

Caputo M.V. 1985. Origem do alinhamento estrutural do Juruá - Bacia do Solimões. In: Simpósio de Geologia da Amazônia, 2, Anais, p. 242-258.

Chardon D. 2003. Strain partitioning and batholith emplacement at the root of a transpressive magmatic arc. Journal of Structural Geology, 25:91-108.
Companhia de Pesquisa e Recursos Minerais (CPRM). 2008. Programa Geologia do Brasil. Integração, atualização e difusão de dados da geologia do Brasil. Mapas geológicos estaduais. Belém, mapa geológico, escala: 1:1.000.000.

Costa J.B.S., Bemerguy R.L., Hasui Y., Borges M.S., Ferreira Júnior C.R.P., Bezerra P.E.L., et al.. 1996. Neotectônica da região Amazônia: aspectos tectônicos, geomorfológicos e deposicionais. Geonomos, 4(2):23-24.

Costa J.B.S., Hasui Y. 1997. Evolução geológica da Amazônia. In: Costa M.L. \& Angélica R.S. (eds.) Contribuições à Geologia da Amazônia. Belém, Sociedade Brasileira de Geologia, p.15-89.

Cunha P.R.C., Gonzaga F.G., Coutinho L.F.C., Feijó F.J. 1994. Bacia do Amazonas. Boletim Geociências Petrobras, 8:47-55.

Dutra A.C.S. 2005. Caracterização petrográfica e química do Diabásio Penatecaua, na região de Monte Alegre (PA). In: Congresso Brasileiro de Geologia, 45, Anais.

Figueira I.F.R. 2011. Tectônica deformadora do Domo de Monte Alegre-Pará. Tese de Doutorado, Universidade Federal do Paraná, Curitiba, 151p.

Fiori A.P. 1997. Introdução à análise da deformação. Curitiba, Ed. UFPR, 249 p.

Freitas, R. C. 2005. Análise estrutural multimatemática do Sistema Petrolifero Irati-Rio Bonito, Bacia do Paraná. Dissertação de Mestrado, Departamento de Ciências da Terra, Universidade Federal do Paraná, Curitiba, 113 p.

Hartt C.F. 1975. Geology and physical geography of Brazil. New York, Krieger Publishing Company, 620 p.

Issler R.S. 1974. Esboço geológico-tectônico do Craton Guaporé. In: SBG. Congresso Brasileiro de Geologia, 28, Resumo das publicações, p.659-665. 
Lange F.W. 1967. Subdivisão biestratigráfica e revisão da coluna siluro-devoniana da bacia do Baixo Amazonas. In: Simpósio sobre Biota Amazônia. Anais, v. 1, p. 215-295

Marques F.O. \& Coelho S. 2001. Rotation of rigid elliptical cylinders in viscous simple shear flow: analogue experiments. Journal of Structural Geology, 23(4):609-617.

Miranda F.P. 1983. Sensoriamento remoto na prospecção de hidrocarbonetos na Bacia do Amazonas. Boletim Técnico Petrobras, 26(4):268-291.

Mizusaki A.M.P., Wanderley J.R., AIRES J.R. 1992. Caracterização do magmatismo básico das bacias do Solimões e Amazonas. Petrobras Internal Report, 57 p.

Montalvão R.M.G., Oliveira A.S. 1975. Geologia branquianticlinal de Monte Alegre e da Rodovia Monte Alegre-Prainha. Belém, Projeto Radam Brasil, 409 p.

Passchier C.W. 1987. Stable positions of rigid objects in non-coaxial flow a study in vorticity analysis. Journal of Structural Geology, 9(5-6):679e690.

Pastana J.M.N., Souza A.M.M., Vale A.G.V., Faria C.A.S., Santos M.E., Assunção P.R.S., et al, 1978. Projeto sulfeto de Alenquer, Monte Alegre, relatório final. Belém, Ministério das Minas e Energias.

Pastana S.M.N. (org.) 1999. Síntese geológica e favorabilidade para tipos de jazimentos minerais do municipio de Monte Alegre-PA. Belém, CPRM/ PRIMAZ, $34 \mathrm{p}$.
Price N.J. \& Cosgrove J.W. 1990. Analysis of geological structures. Cambridge, Cambridge University Press, 502 p.

Rezende W.M.D.E.; Brito C.G. de. 1973. Avaliação geológica da Bacia Paleozóica do Amazonas. In: Congresso Brasileiro de Geologia, 27, Anais, p. 228-245.

Riedel W. 1929. Zur mechanik geologischer brucherscheinungen. Ein beitrag zum problem der fiederspalten. Zentralblat fur Mineralogie. Verlagsbuchhandlung, 1919b:354-368.

Szatmari P. 1983. Amazon rift and Pisco-Juruá fault; their relation to the separation of North America from Gondwana. Geology, 11(5):300-304.

Vasquez M.L., Rosa-Costa L.T., Silva C.M.G., Ricci P.S.F., Barbosa J.P.O., Klein E.L., Lopes E.C.S., Macambira E.M.B., Chaves C.L., Carvalho J.M.A., Oliveira J.G.F., Anjos G.C., Silva H.R. Unidades litoestratigráficas. In: Vasquez M.L., Rosa-Costa L.T. 2008. Geologia e recursos minerais do Estado do Pará: Sistema de Informações Geográficas - SIG. Belém, CPRM, p. 113-215.

WinTensor. 2011. WinTensor version 2.2.8. Tervuren, 2001.

Zalán P.V. 1991. Influence of Pre-Andean Orogenies on the Paleozoic Intracratonic Basins of South America. In: Simpósio Bolivariano, 4, Memórias.

Manuscrito ID 22618

Recebido em: 18/08/2011

Aprovado em: 28/06/2012 